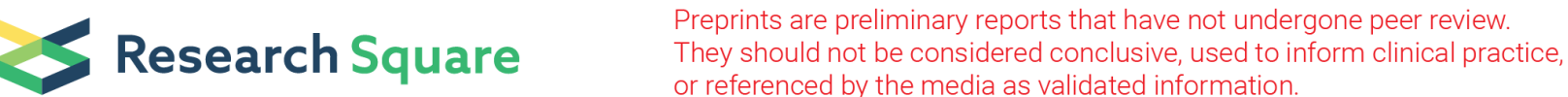

\section{Bortezomib in combination with fludarabine and cyclophosphamide for patients with relapsed or refractory mantle-cell lymphoma: results of the LYM- 4003 study}

\author{
Xiao-xiao Wang \\ Sun Yat-sen University Cancer Center \\ Yan Gao \\ Sun Yat-sen University Cancer Center \\ Jie Jin
}

Zhejiang University School of Medicine First Affiliated Hospital

Jun-ning Cao

Fudan University Shanghai Cancer Center

Ji-feng Feng

Jiangsu Cancer Hospital

Hua-qing Wang

Tianjin People's Hospital

Hui-lai Zhang

Tianjin cancer Hospital

Qing-qing Cai

Sun Yat-sen University Cancer Center

\section{Zhi-ming Li}

Sun Yat-sen University Cancer Center

Hui-qiang Huang ( $\nabla$ huanghq_sysucc@163.com )

Sun Yat-sen University Cancer Center

\section{Research article}

Keywords: Bortezomib, fludarabine and cyclophosphamide, mantle cell lymphoma

Posted Date: December 20th, 2019

DOl: https://doi.org/10.21203/rs.2.19411/v1

License: (c) (i) This work is licensed under a Creative Commons Attribution 4.0 International License.

Read Full License 
Page $2 / 20$ 


\section{Abstract}

\section{Background}

The LYM-4003 study was initiated to identify the maximum tolerated dose (MTD) of cyclophosphamide when combined with bortezomib and fludarabine in a phase $1 \mathrm{~b}$ trial, and to assess the efficacy and safety of this combination in a phase 2 trial in patients with relapsed or refractory MCL.

\section{Methods}

Patients with relapsed or refractory MCL who had received at least one previous lines of treatment were enrolled in this single-arm, open-label, phase 1/2 trial at six major cancer centers in China. In phase 1, to identify the MTD of cyclophosphamide, 3 patient cohorts received escalating doses (150, 200, and 250 $\mathrm{mg} / \mathrm{m} 2$ ) of intravenous cyclophosphamide on days 1,2 of each 28-day cycle. Patients also received bortezomib $1.3 \mathrm{mg} / \mathrm{m} 2$ on days 1, 4, 8 and 11, fludarabine $25 \mathrm{mg} / \mathrm{m} 2$ on days 1, 2, 3 of each 28-day cycle. In phase 2 study, patients received bortezomib and fludarabine plus the MTD of cyclophosphamide. Treatment in both phases to maximum 6 cycles of chemotherapy, continued until disease progression, or severe toxicity. The primary endpoint was overall response. The secondary endpoint was survival. We used the Kaplan-Meier method to estimate response duration, progression-free survival, and overall survival. Analysis was by intention to treat population.

Results

40 patients were enrolled between April 8, 2011 and October 10, 2015, 9 in phase 1 and 34 (including three patients who received the MTD of cyclophosphamide in phase 1) in phase 2 . In phase 1 , we identified the MTD as $250 \mathrm{mg} / \mathrm{m} 2$ cyclophosphamide. In phase 2, grade 3-4 hematological toxicities included thrombocytopenia, leucopenia, neutropenia, and lymphopenia. Among 32 patients in phase 2, 23 (72\%) had an overall response: $10(31 \%)$ had a complete response and $13(41 \%)$ had a partial response. The median follow-up time was 31.6 months. The median response duration was 26.3 months. The median progression-free survival was 21 months (95\% Cl 7.3-34.7), and the median overall survival was 32.4 months (95\% Cl 17.8-47.0).

Conclusions

Bortezomib in combination with fludarabine and cyclophosphamide is highly effective and well tolerated for patients with relapsed or refractory MCL. Trial registration ClinicalTrials.gov NCT01322776 (Registered on March 25, 2011)

\section{Introduction}

Mantel cell lymphoma (MCL) is a distinct subset of B-cell non-Hodgkin's lymphoma characterized by cyclin D1 overexpression resulting from the $t(11 ; 14)(q 13 ; q 32)$ translocation [1-3]. MCL represents an aggressive form of non-Hodgkin's lymphoma, and is incurable with the current front-line treatments. 
Although high-intensity chemotherapy plus stem-cell transplant appears beneficial for progression-free survival (PFS), the median overall survival (OS) is approximately 3 years from diagnosis [4-6].

Recurrence despite high response rates to front-line regimens, often occurred with typical short duration of response (DOR) [2, 5]. New approaches are urgently needed.

Fludarabine is one of the most active agent in low-grade lymphoma, achieving a overall response rate (ORR) of $31 \%$ in relapsed or refractory MCL [7-9]. Fludarabine in combination with cyclophosphamide (FC)/mitoxantrone (FCM) showed an ORR of $46-67 \%$, inducing better quality and more durable response in pre-treated MCL [10-12]. Bortezomib is approved for the treatment of patients with relapsed or refractory MCL with an ORR and CR rate of $30 \%$ and $8 \%$, respectively [13-17]. Results of synergistic cytotoxic effects of fludarabine and bortezomib have been shown in pre-clinical studies $[18,19]$.

On the basis of these preclinical data, we hypothesized that the combination of bortezomib and FC might have more antitumor activity than either drugs alone for patients with relapsed or refractory MCL. To test this hypothesis, we initiated a single-arm, open-label, phase $1 \mathrm{~b} / 2$ clinical trial to identify the maximum tolerated dose (MTD) of cyclophosphamide when combined with bortezomib and fludarabine and to assess the efficacy and safety of this combination in patients with relapsed or refractory MCL.

\section{Methods}

\section{Patients}

Patients with relapsed or refractory $\mathrm{MCL}$ who met the following criteria were eligible for this study: confirmed tissue diagnosis of MCL with CD20 and cyclin D1 positivity; had undergone one or two previous lines of treatment; and had an Eastern Cooperative Oncology Group performance status score of 2 or less. Additional eligibility criteria included an absolute neutrophil count of $\geq 1.5 \times 10^{9}$ cells per $L$, and a platelet count of $\geq 75 \times 10^{9}$ cells per $L$, aspartate aminotransferase and alanine aminotransferase concentrations of less than two times the upper limit of normal, and a creatinine clearance of more than $50 \mathrm{~mL} / \mathrm{min}$. A washout period of 4 weeks since previous therapy was required. Patients were excluded

if they had grade 2 or higher peripheral neuropathy, signs of severe congestive heart failure (New York Heart Failure Guidelines Class III/IV) or active infection were present. Patients were also excluded if there was evidence that the lymphoma had involved the central nervous system, other condition likely to interfere with participation in this clinical study. Patients were excluded if they had received prior treatment with bortezomib (Complete eligibility and exclusion criteria are provided in the Supplementary Appendix).

This study was conducted in accordance with the Declaration of Helsinki and the International Conference on Harmonization Guidelines for Good Clinical Practice. This study protocol was approved by the institutional review board of the Sun Yat-sen University Cancer Center ethic committee (Reference 
number: YP2010170) and institutional review boards at each participant centers. Informed written consent was obtained from all participants before enrolment.

\section{Procedures}

In phase $1 \mathrm{~b}$, patients were sequentially enrolled in three cohorts to receive escalating of doses of $150 \mathrm{mg} / \mathrm{m}^{2}, 200 \mathrm{mg} / \mathrm{m}^{2}$, and $250 \mathrm{mg} / \mathrm{m}^{2}$ of intravenous cyclophosphamide by a $3+3$ algorithm respectively. There were no intra-patient dose escalations. Patients received cyclophosphamide daily on days $1-2$. Bortezomib was given at $1.3 \mathrm{mg} / \mathrm{m}^{2}$ on days $1,4,8$ and 11 in bolus intravenous infusion while $25 \mathrm{mg} / \mathrm{m}^{2}$ of Fludarabine on days 1-3 administered intravenously every 28-day per cycle.

Patients treated at the MTD of cyclophosphamide in phase 1 were counted as the first patients enrolled in the phase 2 study. In phase 2, patients received cyclophosphamide at the MTD, $1.3 \mathrm{mg} / \mathrm{m}^{2}$ of intravenous push over bortezomib on days 1, 4, 8, and 11; as well as $25 \mathrm{mg} / \mathrm{m}^{2}$ of intravenous fludarabine on days 13 of each 28-day cycle. Patients in both phases who achieved complete response (CR) or partial response (PR) continued to receive maximum for six cycles of B-FC, patients who experienced stable disease (SD) discontinued treatment after four cycles of chemotherapy. Recombinant granulocyte colony-stimulating factor (G-CSF; 5 mg/kg subcutaneously) was recommended in the event of severe neutropenia or febrile neutropenia. Prophylactic antimicrobial treatment was administered at the clinical judgement of the treating physician. If the patient experienced febrile neutropenia, grade 4 neutropenia lasting more than 7 days, a platelet counts less than $10 \times 10^{9} / \mathrm{L}$, or any grade 3 non-haematological toxicity considered by investigator to be related to bortezomib, then bortezomib was to be held for up to 14 days until events recovered, with a $25 \%$ reduction in the planned does in the next cycle. On any day of bortezomib administration during a cycle (other than day 1) of each cycle, the patient must have platelet count $\geq 25$ $\times 10^{9}$ cells per $L$, and absolute neutrophil count of $\geq 0.75 \times 10^{9}$ cells per $L$. If the above criteria are not met, bortezomib can be held for up to 2 days. Doses of bortezomib need to be held within a cycle would be skipped and would not be made up later in the cycle. Patients who experienced bortezomib-related neuropathic pain or peripheral sensory neuropathy were managed with dose reductions summarized as follows: grade 1 pain or grade 2 neuropathy, decrease dose to $1.0 \mathrm{mg} / \mathrm{m}^{2}$; grade 2 pain or grade 3 neuropathy, hold bortezomib until resolution and resume at dose of $0.7 \mathrm{mg} / \mathrm{m}^{2}$. Bortezomib was discontinued for grade 4 neuropathy. Patients discontinued treatment in the event of disease progression, unacceptable or unmanageable adverse events, or withdrawal of consent.

\section{Assessments}

The incidence and severity of adverse events (AEs), coded using the Medical Dictionary for Regulatory Activities, were assessed according to the National Cancer Institute Common Terminology Criteria for Adverse Events version 3.0. 
Dose-limiting toxicities (DLTs) were defined as grade 4 neutropenia lasting for $>7$ days; febrile neutropenia of any duration; grade 4 thrombocytopenia lasting for > 14 days despite holding treatment; grade 3 to 4 thrombocytopenia associated with grade $>1$ bleeding; grade $\geq 3$ nonhematologic toxicity (excluding nausea, vomiting, diarrhea, fatigue lasting $<14$ days, increased serum creatinine, or electrolyte abnormalities that were not clinically significant and required no treatment); grade $\geq 3$ acute kidney injury lasting > 72 hours; and grade $\geq 3$ nausea, vomiting, or diarrhea uncontrolled by maximal antiemetic/antidiarrheal medication. The MTD of cyclophosphamide was defined as the highest cyclophosphamide dose at which $<33 \%$ of patients experienced a treatment-related DLT during the first 28-day cycle of treatment in phase 1 study.

The primary efficacy endpoint was the ORR (CR or PR). Response to treatment was assessed according to guidelines developed by an international workshop on lymphoma response criterial [20], with restaging after every two cycles by CT scan and bone marrow biopsies. Both a regular radiological assessment and subsequent reassessment by a designated radiologist (Chao-mei Ruan) were done. The secondary endpoint was survival.

\section{Statistical analysis}

In phase 1, the MTD of cyclophosphamide when combined with bortezomib and fludarabine was identified by a $3+3$ algorithm. We used the Kaplan-Meier method to estimate response duration, progression-free survival (PFS), and overall survival (OS). Analyses were by intention-to-treat population. Response duration was calculated from the response date to the date of relapse, disease progression, or death. Eligible patients who achieved PR or better and who requested subsequent consolidation with SCT were censored for all response assessments at the time of SCT. For the response duration calculation, responders who went off study for any reason other than disease progression or death were censored on the last CT date. Responders who did not experience disease progression but died of another reason were censored at the date of death. Responders who were still actively on study were censored at the survival date or the last CT date.

OS was defined as the time from study entry until death due to any cause, or until the last survival date if still alive. PFS was defined as the time from the start of treatment until lymphoma progression or death regardless of cause. Patients who were still actively on the study were censored at the survival date or the last CT date. The statistical calculations were done with IBM SPSS version 25.0.

\section{Role of the funding source}

Xian-Janssen provided free bortezomib and financial support. The sponsor of the study had no role in data collection, data analysis, or data interpretation. This investigator-initiated study was designed by the corresponding author who worked with co-authors at The Sun Yat-sen University Cancer Center and other hospitals. We communicated and discussed the study design with the sponsor, but this did not lead to alteration of the study design. The sponsor reviewed the manuscript before submission and provided 
grammatical revisions. The corresponding author had full access to all the data in the study and had final responsibility for the decision to submit for publication.

\section{Results}

\section{Patients and enrollment}

Between April 8, 2011 and November 7, 2011, 9 patients (per 3 patients at each dose level) were enrolled in the phase 1 portion of the study, $83 \%$ of whom were men (Table 1). The median age was 60.5 years (range 41-74). Eight patients had one previous treatment and one patient had second prior lines of treatment. $89 \%$ of patient had received previous rituximab-containing treatments. 
Table 1

Demographics and baseline characteristics of patients in phase 1 and phase 2

\begin{tabular}{|c|c|c|c|}
\hline & $\begin{array}{l}\text { Phase } 1 \\
(n=9)\end{array}$ & $\begin{array}{l}\text { Phase } 2 \\
(n=34)\end{array}$ & $\begin{array}{l}\text { Phase } 2 \text { plus phase } 1 \text { patients } \\
(n=40)\end{array}$ \\
\hline Age (years) & $60(41-74)$ & $60(31-75)$ & $60(31-75)$ \\
\hline \multicolumn{4}{|l|}{ Sex } \\
\hline Male & $8(89 \%)$ & $27(79 \%)$ & $32(80 \%)$ \\
\hline Female & $1(11 \%)$ & $7(21 \%)$ & $8(20 \%)$ \\
\hline ECOG & $9(100 \%)$ & $32(94 \%)$ & $38(95 \%)$ \\
\hline \multicolumn{4}{|l|}{ Stage at diagnosis } \\
\hline II & $2(22 \%)$ & $2(6 \%)$ & $4(10 \%)$ \\
\hline III & $6(67 \%)$ & $20(59 \%)$ & $24(60 \%)$ \\
\hline IV & $1(11 \%)$ & $12(35 \%)$ & $12(30 \%)$ \\
\hline \multicolumn{4}{|l|}{ MIPI risk category } \\
\hline Low & $5(56 \%)$ & $21(62 \%)$ & $24(60 \%)$ \\
\hline Intermediate & $3(33 \%)$ & $11(32 \%)$ & 13(33\%) \\
\hline High & $1(11 \%)$ & $2(6 \%)$ & $3(7 \%)$ \\
\hline \multicolumn{4}{|l|}{ Ki67 index (\%) } \\
\hline$<30$ & $5(56 \%)$ & $13(38 \%)$ & $15(38 \%)$ \\
\hline$\geq 30$ & $4(44 \%)$ & $18(53 \%)$ & $20(50 \%)$ \\
\hline Unknown & $0(0 \%)$ & $3(9 \%)$ & $5(12 \%)$ \\
\hline Bone marrow involvement & $1(11 \%)$ & $6(18 \%)$ & $6(15 \%)$ \\
\hline High lactate dehydrogenase & $3(33 \%)$ & $9(26 \%))$ & $11(28 \%)$ \\
\hline \multicolumn{4}{|l|}{ Numbers of previous therapy } \\
\hline 1 & $7(78 \%)$ & $19(56 \%)$ & $21(53 \%)$ \\
\hline 2 & $2(22 \%)$ & $15(44 \%)$ & $19(47 \%)$ \\
\hline
\end{tabular}

Abbreviations: MIPI, mantle cell international prognostic index; ECOG, Eastern Cooperative Oncology Group; R-HyperCVAD/MA = rituximab-hyper-cyclophosphamide, vincristine, doxorubicin, dexamethasone alternating with rituximab, methotrexate, and cytarabine. R-CHOP = rituximab plus cyclophosphamide, doxorubicin, vincristine, prednisone; $\mathrm{BR}=$ bendamustine, rituximab; $\mathrm{AHSCT}=$ atologous stem cell transplantation. *Phase 2 included 3 patients from phase 1 who received $250 \mathrm{mg} / \mathrm{m}^{2}$ cyclophosphamide. 


\begin{tabular}{|c|c|c|c|}
\hline & $\begin{array}{l}\text { Phase } 1 \\
(n=9)\end{array}$ & $\begin{array}{l}\text { Phase } 2 \\
(n=34)\end{array}$ & $\begin{array}{l}\text { Phase } 2 \text { plus phase } 1 \text { patients } \\
(n=40)\end{array}$ \\
\hline \multicolumn{4}{|c|}{ Type of previous therapy } \\
\hline $\mathrm{R}-\mathrm{CHOP}$ & $9(100 \%)$ & $22(65 \%)$ & $24(60 \%)$ \\
\hline R-HyperCVAD/MA & $1(11 \%)$ & $2(6 \%)$ & $2(5 \%)$ \\
\hline BR & $0(0 \%)$ & $1(3 \%)$ & $1(3 \%)$ \\
\hline $\mathrm{CHOP}$ & $0(0 \%)$ & $9(26 \%)$ & $9(22 \%)$ \\
\hline ASCT & $0(0 \%)$ & $1(3 \%)$ & $1(3 \%)$ \\
\hline \multicolumn{4}{|c|}{$\begin{array}{l}\text { Abbreviations: MIPI, mantle cell international prognostic index; ECOG, Eastern Cooperative Oncology } \\
\text { Group; R-HyperCVAD/MA = rituximab-hyper-cyclophosphamide, vincristine, doxorubicin, } \\
\text { dexamethasone alternating with rituximab, methotrexate, and cytarabine. R-CHOP = rituximab plus } \\
\text { cyclophosphamide, doxorubicin, vincristine, prednisone; BR = bendamustine, rituximab; AHSCT = } \\
\text { atologous stem cell transplantation. *Phase } 2 \text { included } 3 \text { patients from phase } 1 \text { who received } \\
250 \mathrm{mg} / \mathrm{m}^{2} \text { cyclophosphamide. }\end{array}$} \\
\hline
\end{tabular}

Patients in phase 1 received a total of 40 cycles (median 4, range 2-6) of treatment. The most common grade $1-2$ hematological adverse events $(\geq 20 \%)$ in phase 1 were anemia, leucopenia, thrombocytopenia and lymphopenia (Table 2). Grade 3-4 hematological adverse events were thrombocytopenia, leucopenia, neutropenia, and lymphocytopenia. The most common grade 1-2 non-hematological adverse events ( $\geq 20 \%$ ) were fatigue, anorexia, nausea, non-neutropenic infection, increased liver function, and neuropathy. Grade 3-4 non-hematological adverse events included non-neutropenic infection, limb pain (one event, related to zoster). 
Table 2

Common adverse events in phase $2(n=33)$

\begin{tabular}{|lllll|}
\hline \multicolumn{1}{|l}{ Grade 1} & Grade 2 & Grade 3 & Grade 4 \\
\hline Haematological events & & & & \\
\hline Leucopenia & $3(33 \%)$ & $3(33 \%)$ & $2(22 \%)$ & $0(0 \%)$ \\
\hline Thrombocytopenia & $1(11 \%)$ & $0(0 \%)$ & $3(33 \%)$ & $0(0 \%)$ \\
\hline Anemia & $1(11 \%)$ & $4(44 \%)$ & $3(33 \%)$ & $0(0 \%)$ \\
\hline Lymphopenia & $3(33 \%)$ & $4(44 \%)$ & $0(0 \%)$ & $0(0 \%)$ \\
\hline Non-haematological events & & & & \\
\hline Fatigue & $0(0 \%)$ & $2(22 \%)$ & $5(56 \%)$ & $2(22 \%)$ \\
\hline Pruritus & $3(33 \%)$ & $1(11 \%)$ & $0(0 \%)$ & $0(0 \%)$ \\
\hline Cough & $1(11 \%)$ & $0(0 \%)$ & $0(0 \%)$ & $0(0 \%)$ \\
\hline Anorexia & $0(0 \%)$ & $1(11 \%)$ & $0(0 \%)$ & $0(0 \%)$ \\
\hline Non-neutropenic infections & $0(0 \%)$ & $2(22 \%)$ & $0(0 \%)$ & $0(0 \%)$ \\
\hline Increased liver function & $1(11 \%)$ & $2(22 \%)$ & $0(0 \%)$ & $0(0 \%)$ \\
\hline Neuropathy & $6(67 \%)$ & $0(0 \%)$ & $0(0 \%)$ & $0(0 \%)$ \\
\hline Myalgia & $1(11 \%)$ & $0(0 \%)$ & $0(0 \%)$ & $0(0 \%)$ \\
\hline
\end{tabular}

Three patients from phase 1 who received $250 \mathrm{mg} / \mathrm{m}^{2}$ cyclophosphamide on days $1-2$ (the established MTD) were counted as phase 2 patients. For phase 2, an additional 31 patients were enrolled from November 29, 2011 to October 10, 2015 for a total of 34 patients treated at the MTD. 85\% of these 34 patients were men. The median age was 60.5 years (range $31-75$ ). $88 \%$ of patients in phase 2 had received previous rituximab-containing treatments. Two patients were taken out from responses evaluation because of protocol violation $(n=1)$, and treatment-related toxicities before response evaluation $(n=1)$ (Fig. 1). The latter patient was a 72 years old man with high tumor burden, he developed grade 4 leucopenia, grade 3 thrombocytopenia, and febrile neutropenia. The patient died failed to all kind of neccessary management eventually.

152 cycles of study treatment were delivered to the 32 patients in phase 2 . Common ( $\geq 20 \%$ ) grade 1-2 haematological adverse events included lymphopenia, neutropenia, leucopenia, anemia, thrombocytopenia (Table 3). Grade 3-4 haematological adverse events were neutropenia, lymphopenia, leucopenia, anemia, thrombocytopenia, and febrile neutropenia. Common grade 1-2 non-haematological adverse events (experienced by $>50 \%$ of patients) were fatigue, constipation, neuropathy, hyperglycaemia, and diarrhea. Grade 3-4 non-haematological events were rare. 
Table 3

Common adverse events in phase $2(n=33)$

\begin{tabular}{|llllll|}
\hline & Grade 1 & Grade 2 & Grade 3 & Grade 4 & Grade 5 \\
\hline Haematological events & & & & & \\
\hline Leucopenia & $3(9 \%)$ & $14(42 \%)$ & $10(30 \%)$ & $2(6 \%)$ & $0(0 \%)$ \\
\hline Neutropenia & $9(27 \%)$ & $3(9 \%)$ & $6(18 \%)$ & $3(9 \%)$ & $0(0 \%)$ \\
\hline Febrile neutropenia & $0(0 \%)$ & $0(0 \%)$ & $4(12 \%)$ & $0(0 \%)$ & $0(0 \%)$ \\
\hline Thrombocytopenia & $0(0 \%)$ & $16(48 \%)$ & $9(27 \%)$ & $4(12 \%)$ & $0(0 \%)$ \\
\hline Anemia & $19(58 \%)$ & $6(18 \%)$ & $0(0 \%)$ & $0(0 \%)$ & $0(0 \%)$ \\
\hline Lymphopenia & $1(3 \%)$ & $3(9 \%)$ & $12(36 \%)$ & $12(36 \%)$ & $0(0 \%)$ \\
\hline Non-haematological events & & & & & \\
\hline Fatigue & $14(42 \%)$ & $3(9 \%)$ & $1(3 \%)$ & $0(0 \%)$ & $0(0 \%)$ \\
\hline Constipation & $4(12 \%)$ & $0(0 \%)$ & $0(0 \%)$ & $0(0 \%)$ & $0(0 \%)$ \\
\hline Neuropathy & $10(30 \%)$ & $4(12 \%)$ & $1(3 \%)$ & $0(0 \%)$ & $0(0 \%)$ \\
\hline Tinnitus & $3(9 \%)$ & $3(9 \%)$ & $0(0 \%)$ & $0(0 \%)$ & $0(0 \%)$ \\
\hline Pneumonia & $1(3 \%)$ & $0(0 \%)$ & $1(3 \%)$ & $0(0 \%)$ & $0(0 \%)$ \\
\hline Nausea & $2(6 \%)$ & $0(0 \%)$ & $0(0 \%)$ & $0(0 \%)$ & $0(0 \%)$ \\
\hline Myalgia & $5(15 \%)$ & $2(6 \%)$ & $0(0 \%)$ & $0(0 \%)$ & $0(0 \%)$ \\
\hline Infection & $7(21 \%)$ & $3(9 \%)$ & $1(3 \%)$ & $0(0 \%)$ & $0(0 \%)$ \\
\hline Diarrhoea & $0(0 \%)$ & $3(9 \%)$ & $1(3 \%)$ & $0(0 \%)$ & $1(3 \%)$ \\
\hline Hyperuricaemia & $4(12 \%)$ & $1(3 \%)$ & $1(3 \%)$ & $0(0 \%)$ & $0(0 \%)$ \\
\hline Hyperglycaemia & $9(27 \%)$ & $0(0 \%)$ & $0(0 \%)$ & $0(0 \%)$ & $0(0 \%)$ \\
\hline Hypoalbuminaemia & $0(0 \%)$ & $0(0 \%)$ & $0(0 \%)$ & $0(0 \%)$ \\
\hline Elevated liver function & $1(3 \%)$ & $0(0 \%)$ & $0(0 \%)$ & $0(0 \%)$ \\
\hline Raised BUN & $0(0 \%)$ & $1(3 \%)$ & $0(0 \%)$ & $0(0 \%)$ \\
\hline Oedema limb & $0(0 \%)$ & $0(0 \%)$ & $0(0 \%)$ & $0(0 \%)$ \\
\hline
\end{tabular}

Only one patient in phase 2 needed dose reduction of bortezomib because of unrecovered from grade 4 haematological toxicity before next cycle of chemotherapy. Patients received a median of 6 cycles (range 2-6) of chemotherapy. 
32 patients in phase 2 were assessed for response to treatment. At a median follow-up of 31.6 months (13.5-47.4), $23(72 \%, 95 \% \mathrm{Cl} 57-87)$ of 32 patients had an overall response. $10(31 \%, 95 \% \mathrm{Cl} 16-46)$ patients had a complete response and thirteen $(41 \%, 95 \% \mathrm{Cl} 25-57)$ had a partial response (Table 4).

Table 4

Response rates and survival at the maximum tolerated dose in phase 2

\begin{tabular}{|ll|}
\hline & Phase 2 (n= 32) \\
\hline Complete response & $10(31 \%)$ \\
\hline Partial response & $13(41 \%)$ \\
\hline Overall response & $23(72 \%)$ \\
\hline Stable disease & $6(19 \%)$ \\
\hline Progression disease & $3(9 \%)$ \\
\hline Response duration (months) & $26.3(11.8-33.9)$ \\
\hline Progression-free survival (months) & $21.0(95 \% \mathrm{Cl} 7.3-34.7)$ \\
\hline Overall survival (months) & $32.4(95 \% \mathrm{Cl} 17.8-47.0)$ \\
\hline Follow-up time (months) & $31.6(13.5-47.4)$ \\
\hline
\end{tabular}

The median response duration for the 23 patients with an overall response was 26.3 months (11.8-33.9), the median PFS was 21.0 months $(95 \% \mathrm{Cl} 7.3-34.7)$ and the median OS was 32.4 months $(95 \% \mathrm{Cl} 17.8-$ 47.0) (Fig. 2).

\section{Discussion}

In this phase $1 \mathrm{~b} / 2$ study, we identified the MTD of cyclophosphamide to be $250 \mathrm{mg} / \mathrm{m}^{2}$ days $1-2$ when combined with bortezomib and fludarabine. The combination was effective, with an OR of $72 \%$ and $\mathrm{CR}$ of $31 \%$ in patients with relapsed or refractory MCL.

The treatment of patients with relapsed or refractory $M C L$ remains a major challenge [21]. Barr et al. have initiated a phase 1 trial combined bortezomib with fludarabine with or without rituximab for patients with relapsed or refractory indolent $M C L$ based on the hypothesis that bortezomib may potentiate fludarabine activity [22]. The study determined the MTD to be fludarabine $25 \mathrm{mg} / \mathrm{m}^{2}$ on days $1-3$, bortezomib $1.3 \mathrm{mg} / \mathrm{m}^{2}$ on days $1,4,8,11$, and rituximab $375 \mathrm{mg} / \mathrm{m}^{2}$ on day 1 . The most common haematologic toxicity were neutropenia and thrombocytopenia. Grade 3-4 neutropenia and thrombocytopenia were $24 \%$ and $17 \%$, respectively. However, there was no MCL patient enrolled at the MTD dose, so the overall response of this combination therapy in patients with relapsed or refractory MCL was unknown. 
Fludarabine-based combination regimens, with or without rituximab, have shown activity in patients with relapsed or refractory MCL. In our study, approximate $90 \%$ of the patients had received rituximab in previous lines of chemotherapy, we suspect that patients might achieve more benefit from bortezomib than re-challenge of rituximab. FC combined mitoxantrone (FCM) achieved an ORR of $46 \%$ (CR rate of $0 \%$ ) in the treatment of relapsed or refractory $\mathrm{MCL}$ [23]. In our study, the combination of bortezomib and FC was quite effective, with $72 \%$ of patients achieving OR, especially $31 \%$ of patients achieving CR. Furthermore, the response was durable, which inducing a better DOR (26.3 months) and PFS (21 months) compared with either cytotoxic agents alone. These results are in agreement with previous study demonstrating the importance of good quality remissions in MCL as a crucial factor for sustained disease control [24]. This result might imply bortezomib combined FC contributed to the improvement of $\mathrm{CR}$, and inducing deep remission in patients with relapsed or refractory MCL.

Fludarabine was shown to induce a profound depression of CD4 lymphocytes, leading to a long-lasting immune deficiency [25]. Addition of rituximab to FC might have increasing the frequency of infections owing to depletion of CD20-positive B cells [23]. However, we did not observe increasing rates of severe infections by adding bortezomib to fludarabine and cyclophosphamide. Febrile neutropenia was observed in 4 (12\%) patients in phase 2 portion of this study. Frequencies of non-neutropenic infection were low with one patient suffered grade 3 zoster results in the delay of treatment.

Thrombocytopenia was a common adverse event in this study, which related to the clinical nature of platelet-count reduction with bortezomib. But the events mostly were grade 2 and grade 3 thrombocytopenia, no significant bleeding events. One patient needs dose adjustment of bortezomib according to protocol described. After decreasing a dose level of bortezomib to $1 \mathrm{mg} / \mathrm{m}^{2}$, toxicities were satisfied in the follow cycles.

In 2004, Forstpointner and colleagues reported the results from a randomized study of the GLSG, R-FCM revealed an OR of $58 \%$ as compared with $46 \%$ for FCM in patients with relapsed or refractory MCL [23]. However, the data from the present study of the combination of bortezomib and FC seem to be more favourable than R-FCM (71.9\% versus 58\%). The good response might attribute to bortezomib, which inducing $\mathrm{CR}$ of $8 \%$ by single agent in patients with relapsed or refractory MCL. More important, the higher activity of B-FC seem to be translated into improvement of OS with a plateau at 3 years. In 2005, Rummel and colleagues reported the result from a study of bendamustine and rituximab in patients with relapsed or refractory MCL. The combination of bendamustine and rituximab displayed good efficacy in 16 patients with MCL, with a OR of $75 \%$ and CR of $50 \%$, with acceptable toxicity [26]. Another study recruited 7 relapsed patients with MCL who were treated with bendamustine, bortezomib, and rituximab; $71 \%$ ORs were reported [27]. Both the efficacy and safety of this study were comparable to aforementioned regimens in patients with relapsed or refractory MCL. However, randomized trials will be required to determine how important bortezomib is in this combination.

In the novel agents era, new targeted drugs show prominent efficacy in relapsed or refractory MCL. Nevertheless, cytotoxic agents still have its role in MCL with a comparable efficacy and durable response. 
It can therefore be concluded that the addition of bortezomib to fludarabine and cyclophosphamide comprises a highly effective salvage regimen for relapsed and refractory $\mathrm{MCL}$ with moderate toxiccity.

\section{Declarations}

\section{Ethics approval and consent to participate}

The study has been approved by the ethics committee of the Sun Yat-sen University Cancer Center (reference number: YP2010170). This study was conducted in accordance with the Declaration of Helsinki and the International Conference on Harmonization Guidelines for Good Clinical Practice. Institutional Review Board approval was obtained at each study cite. Informed written consent was obtained from all participants before enrolment.

\section{Consent for publication}

Not applicable.

\section{Availability of data and materials}

The authenticity of this article has been validated by uploading the key raw data onto the Research Data Deposit public platform (www.researchdata.org.cn), with the approval RDD number as RDDA2019001348

\section{Competing interests}

We declare no competing interests.

\section{Funding}

This study was financially supported by the Xian-Janssen pharmaceuticals company.

\section{Author's contributions}

$X X W$ and $\mathrm{HQH}$ designed the study. $\mathrm{HQH}, \mathrm{XXW}, \mathrm{YG}, \mathrm{JJ}, \mathrm{JNC}, \mathrm{JFF}, \mathrm{HLZ}, \mathrm{QQC}, \mathrm{ZML}$, and WQJ recruited and cared for patients. XXW and $Y G$ contributed to data collection and data assembly. $X X W, Y G$ and $H Q H$ did the data analyses and wrote the paper. All authors contributed to interpretation of the data, critically revised the manuscript throughout development for intellectual content, approved the final version, and are responsible for the accuracy and integrity of the work.

\section{Acknowledgments}

We appreciate the works by the Lym-4003 study collaborators.

\section{References}


1 Barista I, Romaguera JE, Cabanillas F. Mantle-cell lymphoma. The Lancet Oncology. 2001;2(3):141-8.

2 Williams ME, Densmore JJ. Biology and therapy of mantle cell lymphoma. Current opinion in oncology. 2005;17(5):425-31.

3 Bertoni F, Rinaldi A, Zucca E, Cavalli F. Update on the molecular biology of mantle cell lymphoma. Hematological oncology. 2006;24(1):22-7.

4 Lenz G, Dreyling M, Hiddemann W. Mantle cell lymphoma: established therapeutic options and future directions. Annals of hematology. 2004;83(2):71-7.

5 Witzig TE. Current treatment approaches for mantle-cell lymphoma. Journal of clinical oncology : official journal of the American Society of Clinical Oncology. 2005;23(26):6409-14.

6 Vigouroux S, Gaillard F, Moreau P, Harousseau JL, Milpied N. High-dose therapy with autologous stem cell transplantation in first response in mantle cell lymphoma. Haematologica. 2005;90(11):1580-2.

7 Tam CS, Wolf MM, Januszewicz EH, Prince HM, Westerman D, Seymour JF. Fludarabine and cyclophosphamide using an attenuated dose schedule is a highly effective regimen for patients with indolent lymphoid malignancies. Cancer. 2004;100(10):2181-9.

8 Decaudin D, Bosq J, Tertian G, Nedellec G, Bennaceur A, Venuat AM, et al. Phase II trial of fludarabine monophosphate in patients with mantle-cell lymphomas. Journal of clinical oncology : official journal of the American Society of Clinical Oncology. 1998;16(2):579-83.

9 Cohen BJ, Moskowitz C, Straus D, Noy A, Hedrick E, Zelenetz A. Cyclophosphamide/fludarabine (CF) is active in the treatment of mantle cell lymphoma. Leukemia \& lymphoma. 2001;42(5):1015-22.

10 McLaughlin P, Hagemeister FB, Romaguera JE, Sarris AH, Pate O, Younes A, et al. Fludarabine, mitoxantrone, and dexamethasone: an effective new regimen for indolent lymphoma. Journal of clinical oncology : official journal of the American Society of Clinical Oncology. 1996;14(4):1262-8.

11 Lossos IS, Paltiel O, Polliack A. Salvage chemotherapy using a combination of fludarabine and cyclophosphamide for refractory or relapsing indolent and aggressive non-Hodgkin's lymphomas. Leukemia \& lymphoma. 1999;33(null):155-60.

12 Thomas DW, Owen RG, Johnson SA, Hillmen P, Seymour JF, Wolf MM, et al. Superior quality and duration of responses among patients with mantle-cell lymphoma treated with fludarabine and cyclophosphamide with or without rituximab compared with prior responses to CHOP. Leukemia \& lymphoma. 2005;46(4):549-52.

13 Belch A, Kouroukis CT, Crump M, Sehn L, Gascoyne RD, Klasa R, et al. A phase Il study of bortezomib in mantle cell lymphoma: the National Cancer Institute of Canada Clinical Trials Group trial 
IND.150. Annals of oncology : official journal of the European Society for Medical Oncology. 2007;18(1):116-21.

14 Fisher RI, Bernstein SH, Kahl BS, Djulbegovic B, Robertson MJ, de Vos S, et al. Multicenter phase II study of bortezomib in patients with relapsed or refractory mantle cell lymphoma. Journal of clinical oncology : official journal of the American Society of Clinical Oncology. 2006;24(30):4867-74.

15 Goy A, Younes A, McLaughlin P, Pro B, Romaguera JE, Hagemeister F, et al. Phase II study of proteasome inhibitor bortezomib in relapsed or refractory B-cell non-Hodgkin's lymphoma. Journal of clinical oncology : official journal of the American Society of Clinical Oncology. 2005;23(4):667-75.

16 Strauss SJ, Maharaj L, Hoare S, Johnson PW, Radford JA, Vinnecombe S, et al. Bortezomib therapy in patients with relapsed or refractory lymphoma: potential correlation of in vitro sensitivity and tumor necrosis factor alpha response with clinical activity. Journal of clinical oncology : official journal of the American Society of Clinical Oncology. 2006;24(13):2105-12.

17 O'Connor OA, Wright J, Moskowitz C, Muzzy J, MacGregor-Cortelli B, Stubblefield M, et al. Phase II clinical experience with the novel proteasome inhibitor bortezomib in patients with indolent non-Hodgkin's lymphoma and mantle cell lymphoma. Journal of clinical oncology : official journal of the American Society of Clinical Oncology. 2005;23(4):676-84.

18 Hewamana S, Alghazal S, Lin TT, Clement M, Jenkins C, Guzman ML, et al. The NF-kappaB subunit Rel $A$ is associated with in vitro survival and clinical disease progression in chronic lymphocytic leukemia and represents a promising therapeutic target. Blood. 2008;111(9):4681-9.

19 Duechler M, Linke A, Cebula B, Shehata M, Schwarzmeier JD, Robak T, et al. In vitro cytotoxic effect of proteasome inhibitor bortezomib in combination with purine nucleoside analogues on chronic lymphocytic leukaemia cells. European journal of haematology. 2005;74(5):407-17.

20 Cheson BD, Horning SJ, Coiffier B, Shipp MA, Fisher RI, Connors JM, et al. Report of an international workshop to standardize response criteria for non-Hodgkin's lymphomas. NCI Sponsored International Working Group. Journal of clinical oncology : official journal of the American Society of Clinical Oncology. 1999;17(4):1244.

21 Dreyling M, Lenz G, Hoster E, Van Hoof A, Gisselbrecht C, Schmits R, et al. Early consolidation by myeloablative radiochemotherapy followed by autologous stem cell transplantation in first remission significantly prolongs progression-free survival in mantle-cell lymphoma: results of a prospective randomized trial of the European MCL Network. Blood. 2005;105(7):2677-84.

22 Barr PM, Fu P, Lazarus HM, Horvath N, Gerson SL, Koc ON, et al. Phase I trial of fludarabine, bortezomib and rituximab for relapsed and refractory indolent and mantle cell non-Hodgkin lymphoma. British journal of haematology. 2009;147(1):89-96. 
23 Forstpointner R, Dreyling M, Repp R, Hermann S, Hänel A, Metzner B, et al. The addition of rituximab to a combination of fludarabine, cyclophosphamide, mitoxantrone (FCM) significantly increases the response rate and prolongs survival as compared with FCM alone in patients with relapsed and refractory follicular and mantle cell lymphomas: results of a prospective randomized study of the German Low-Grade Lymphoma Study Group. Blood. 2004;104(10):3064-71.

24 Pott C, Schrader C, Gesk S, Harder L, Tiemann M, Raff T, et al. Quantitative assessment of molecular remission after high-dose therapy with autologous stem cell transplantation predicts long-term remission in mantle cell lymphoma. Blood. 2006;107(6):2271-8.

25 Ross SR, McTavish D, Faulds D. Fludarabine. A review of its pharmacological properties and therapeutic potential in malignancy. Drugs. 1993;45(5):737-59.

26 Rummel MJ, Al-Batran SE, Kim SZ, Welslau M, Hecker R, Kofahl-Krause D, et al. Bendamustine plus rituximab is effective and has a favorable toxicity profile in the treatment of mantle cell and low-grade non-Hodgkin's lymphoma. Journal of clinical oncology : official journal of the American Society of Clinical Oncology. 2005;23(15):3383-9.

27 Friedberg JW, Vose JM, Kelly JL, Young F, Bernstein SH, Peterson D, et al. The combination of bendamustine, bortezomib, and rituximab for patients with relapsed/refractory indolent and mantle cell non-Hodgkin lymphoma. Blood. 2011;117(10):2807-12.

\section{Figures}




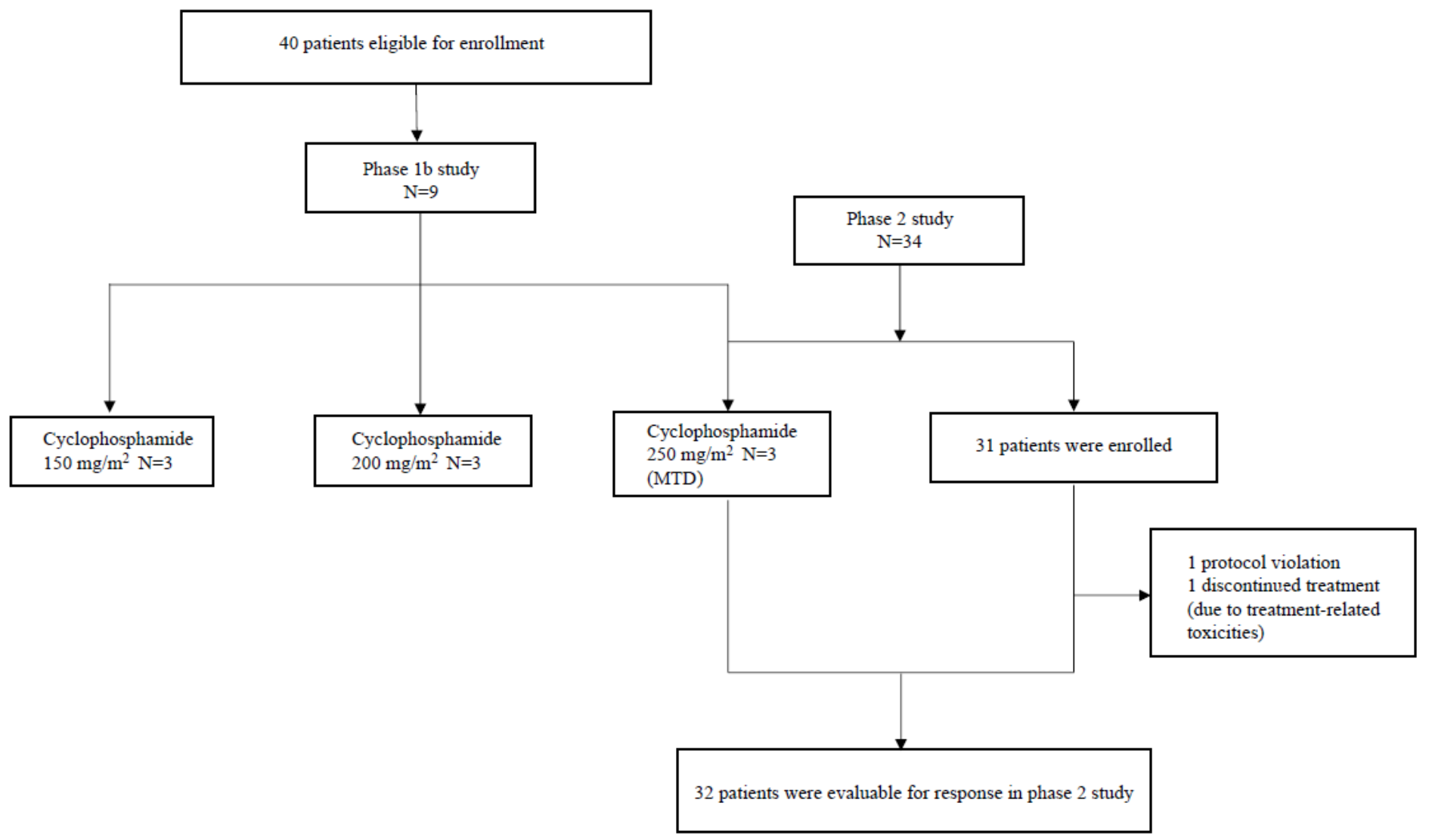

Figure 1

Patient flow diagram 


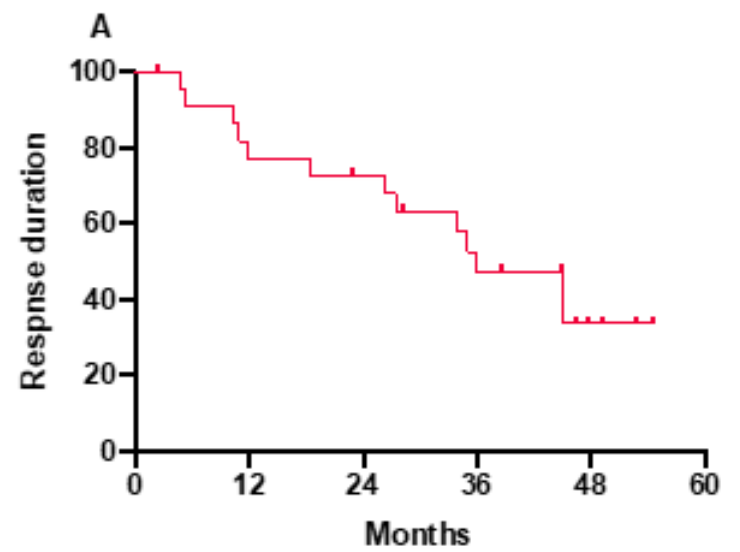

$\begin{array}{llllll}\text { Number at risk } & 23 & 18 & 16 & 10 & 4\end{array}$

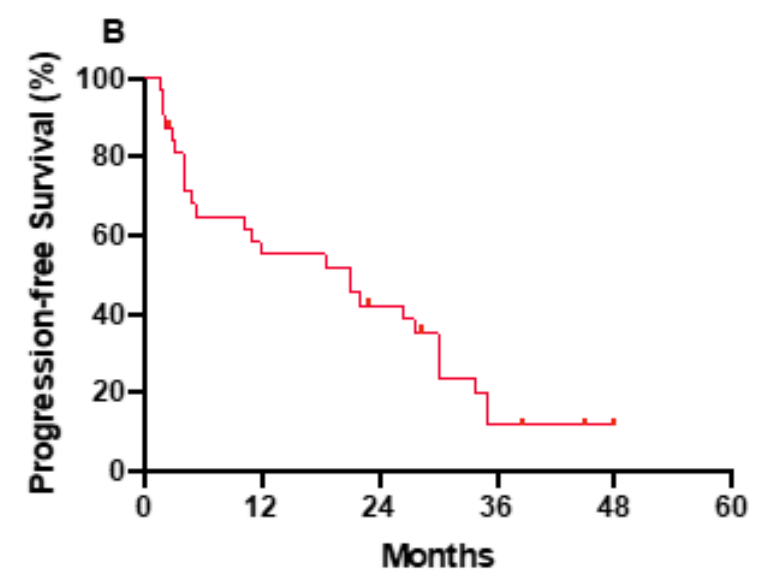

$\begin{array}{llllll}\text { Number at risk } & 32 & 20 & 12 & 3 & 0\end{array}$

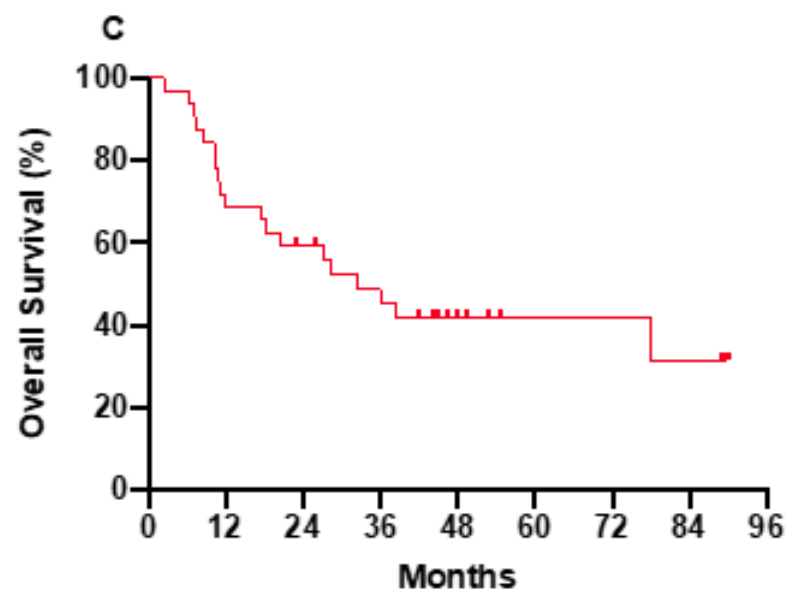

$\begin{array}{llllllllll}\text { Number at risk } & 32 & 20 & 18 & 13 & 7 & 4 & 4 & 3 & 0\end{array}$

\section{Figure 2}

Response duration, progression-free survival, and overall survival. (A) Response duration of 23 patients who achieved an overall response, (B) progression-free survival, and (C) overall survival of 32 patients enrolled in phase 2 .

\section{Supplementary Files}


This is a list of supplementary files associated with this preprint. Click to download.

- Protocol26866138LYM4003XJP20110505Final.doc 